\title{
Musculoskeletal Symptoms and Associated Risk Factors in a Large Sample of Chinese Workers in Henan Province of China
}

\author{
Shanfa Yu, MD, PhD, ${ }^{1}$ Ming-Lun Lu, PhD, ${ }^{2 *}$ Guizhen Gu, MD, ${ }^{1}$ Wenhui Zhou, MD, ${ }^{1}$ \\ Lihua He, MD, $\mathrm{PhD}^{3}$ and Sheng Wang, $\mathrm{MD}^{\mathrm{PhD}^{3}}$
}

\begin{abstract}
Objective To investigate the one-year prevalence of musculoskeletal symptoms and associated risk factors in a large sample of Chinese workers in various industrial settings.

Methods A total of 5,338 (3,632 males and 1,706 females) workers from 13 companies participated in this study. Musculoskeletal symptoms in different body regions in the previous year and their risk factors were assessed by a self-reported questionnaire. Logistic regression analyses were performed to estimate the individual, work-related physical and psychosocial risk factors for the musculoskeletal symptoms.

Results The most commonly affected body regions among the workers were lower back (59.7\%), neck (48.6\%), shoulders (38.8\%), and wrists (33.5\%). Female workers had greater prevalence of musculoskeletal symptoms in the neck, shoulders, and wrists than male workers. Results of multivariate analyses indicated that individual, workrelated physical and psychosocial factors were associated with the musculoskeletal symptoms.

Conclusion The results suggest that interventions aimed at reducing musculoskeletal symptoms in the Chinese working population should take into account multiple risk areas including individual, physical job characteristics and work-related psychosocial factors. Am. J. Ind. Med. 55:281-293, 2012. (c) 2011 Wiley Periodicals, Inc.
\end{abstract}

KEY WORDS: musculoskeletal symptoms; Chinese workers; physical job characteristics; psychosocial factors; personal factors

\section{INTRODUCTION}

${ }^{1}$ Henan Provincial Institute of Occupational Health, Zhengzhou, Henan, China

${ }^{2}$ National Institute for Occupational Safety and Health, Cincinnati, Ohio

${ }^{3}$ Peking University Health Science Center, Beijing, China

Disclosure Statement: The authors report no conflicts of interest. The findings in this report are those of the authors and do not necessarily represent the views of the authors' affiliated institutes.

${ }^{*}$ Correspondence to: Ming-Lun Lu, PhD, The National Institute for Occupational Safety and Health, 4676 Columbia Parkway, MSC-24, Cincinnati,0H.E-mail:mlu@cdc.gov

Accepted 19 0ctober 2011

D0l 10.1002/ajim.21037. Published online 28 November 2011 in Wiley Online Library (wileyonlinelibrary.com).
Work-related musculoskeletal disorders (WMSDs) are a major health problem and an economic burden in many industrialized nations [Coyte et al., 1998; Cassou et al., 2002; Thienoff, 2002; Liberty Mutual Research Institute for Safety, 2009; United States Bureau of Labor Statistics, 2009]. In China, WMSDs are not included as part of the workers' compensation system. Therefore, little attention has been devoted to Chinese workers for this health problem found in many industrialized nations. A small number of researchers reported the prevalence of WMSDs in 
China [Jin et al., 2004; Smith et al., 2004; Chen et al., 2005]. However, generalizability of these study results is limited due to a small sample size $(\mathrm{N}=282-561)$ for a limited number of specific occupations $(\mathrm{N}=1-3)$. There is a need to further investigate the scope of the WMSD problem in China with different industrial settings or occupations, as the problem may become a serious workplace concern indicated by the previous studies.

In a recent review of 63 selected longitudinal studies on WMSDs, physical work, smoking, excess body weight, psychosocial work demands, and co-morbidities were found to have strong evidence associated with the development of WMSDs [da Costa and Vieira, 2010]. The results agree with the findings from two earlier major reviews on WMSDs [NIOSH, 1997; NAS, 2001]. To investigate WMSDs in a large sample of Chinese working population in different industrial settings, a cross-sectional study was conducted to collect comprehensive information about individual and job conditions in relation to musculoskeletal symptoms in China. It was hypothesized that musculoskeletal symptoms in Chinese workers were associated with individual, work-related physical and psychosocial risk factors.

\section{METHODS}

\section{Subjects}

The study was conducted in Henan province, the most populated province (population $=\sim 100$ million) in China. Workers on the payroll of each participating company were recruited. Of 6,711 recruited workers, 5,909 (88\%) agreed to participate in the study. The participants received a standardized questionnaire in their workplaces and were given 45 min to complete it. A portion (9.6\%) of the participants with greater than or equal to three missing responses to the questions on a questionnaire scale was excluded from the data analysis, resulting in the final questionnaire response rate of $79.6 \%$ [Yu et al., 2000; Ahola and Hakanen, 2007]. The questionnaire consisted of four parts: (1) Demographic and job information, (2) musculoskeletal symptoms, (3) physical job characteristics, and (4) work-related psychosocial factors. Reported symptoms were limited to the past 12 months. Data were collected anonymously between November 2008 and June 2009. The study protocol was approved by the Medical Ethics Committee of the Henan Provincial Institute of Occupational Health. The demographics and job information of the participants are shown in Table I.

\section{Surveys of Musculoskeletal Symptoms}

Musculoskeletal symptoms were assessed by a questionnaire adapted from the Dutch musculoskeletal questionnaire [Hildebrandt et al., 2001]. The reliability and validity of the questionnaire has been established in a previous study [Yang et al., 2009]. The surveyed symptoms in this study included pain and discomfort. Discomfort was explained to participants as being any unpleasant subjective sensation including numbness, soreness, and/or any limitation of physical activity. Participants who responded to the following question were considered to have a musculoskeletal symptom in a specific body region (the neck, shoulders, wrists/hands, elbows, low back, hip, knees, or ankles/feet): "Did you have pain and discomfort in the body region lasting more than $24 \mathrm{hr}$ in the past 12 months?" A diagram for the different body regions was provided to assist the participants in accurately identifying their pain/discomfort in the regions. The answer to each question was dichotomous (yes/no).

\section{Evaluation of Individual Factors}

Individual factors evaluated in the study included eight items: (1) Gender, (2) age (four categories: $\leq 24,25$ $30,31-40$, and $\geq 41$ years), (3) length of employment (four categories: $\leq 5,6-15,16-20$, and $\geq 21$ years), (4) education level (four categories: Elementary school, junior high school, high school, and college/university); (5) job title (four categories: Production worker, assistant worker, technician, or manager), (6) cigarette smoking (yes, no), (7) alcohol dinking (yes, no), and (8) body mass index (BMI) (underweight: BMI $<18.5 \mathrm{~kg} / \mathrm{m}^{2}$; normal: $18.5 \leq$ BMI $<24 \mathrm{~kg} / \mathrm{m}^{2}$; overweight: $24 \mathrm{~kg} / \mathrm{m}^{2} \leq$ BMI $<28 \mathrm{~kg} /$ $\mathrm{m}^{2}$; and obesity: BMI $\geq 28 \mathrm{~kg} / \mathrm{m}^{2}$ ), as recommended by the Ministry of Health of The People's Republic of China in 2009.

Two broad "mood state" variables-affectivity and depression-were evaluated in the study [Watson and Clark, 1988]. Both positive effect and negative effect were measured by five questions, respectively [Bradburn, 1969]. The answer (yes, no) to each question was provided and the total score of the answers (yes: 1; no: 0) to the five questions was calculated [Bradburn, 1969; Yu et al., 2000]. An example of the question items for negative effect is "During the past few weeks, did you ever feel upset because someone criticized you?" An example of the question items for positive affect is "During the past few weeks, did you feel proud that someone praised what you had done?" Cronbach's alphas of the scores for positive and negative affect variables were 0.81 and 0.80 , respectively.

Depression was measured with the Chinese version of the Center for Epidemiological Studies Depression (CESD) Scale [Radloff, 1977]. The CES-D consists of 20 items, and all items were answered on a scale of four options ranging from 0 (never), 1-2 days per week, 3-4 days per 
TABLE I. Demographics and Job Information of Study Participants $(N=5,338)$

\begin{tabular}{|c|c|c|c|c|c|c|}
\hline \multirow[b]{2}{*}{ Variables } & \multicolumn{2}{|c|}{ Male } & \multicolumn{2}{|c|}{ Female } & \multicolumn{2}{|c|}{ Total } \\
\hline & $\mathbf{n}$ & $\%$ & $\mathbf{n}$ & $\%$ & $\mathbf{n}$ & $\%$ \\
\hline & 3632 & 68.0 & 1706 & 32.0 & 5338 & 100 \\
\hline \multicolumn{7}{|l|}{ Educational level } \\
\hline Elementary & 30 & 0.8 & 15 & 0.9 & 45 & 0.8 \\
\hline Junior high school & 720 & 19.8 & 378 & 22.2 & 1098 & 20.6 \\
\hline Highschool & 2071 & 57.0 & 930 & 54.5 & 3001 & 56.2 \\
\hline College or university & 811 & 22.3 & 383 & 22.5 & 1194 & 22.4 \\
\hline \multicolumn{7}{|l|}{ Job title } \\
\hline Production worker & 3164 & 87.1 & 1366 & 80.1 & 4530 & 84.9 \\
\hline Assistant worker & 161 & 4.4 & 104 & 6.1 & 265 & 5.0 \\
\hline Technician & 218 & 6.0 & 161 & 9.4 & 379 & 7.1 \\
\hline Manager & 89 & 2.4 & 75 & 4.4 & 164 & 3.1 \\
\hline \multicolumn{7}{|l|}{ Age } \\
\hline$\leq 24$ & 806 & 22.2 & 279 & 16.4 & 1085 & 20.3 \\
\hline $25-30$ & 790 & 21.7 & 238 & 14.0 & 1028 & 19.3 \\
\hline $31-40$ & 1298 & 35.7 & 695 & 40.7 & 1993 & 37.3 \\
\hline$\geq 41$ & 738 & 20.3 & 494 & 29.0 & 1232 & 23.1 \\
\hline \multicolumn{7}{|l|}{ Cigarette smoking } \\
\hline Yes & 1935 & 53.3 & 35 & 2.1 & 1970 & 36.9 \\
\hline No & 1697 & 46.7 & 1671 & 97.9 & 3368 & 63.1 \\
\hline \multicolumn{7}{|l|}{ Alcohol drinking } \\
\hline Yes & 2062 & 56.8 & 80 & 4.7 & 2142 & 40.1 \\
\hline No & 1570 & 43.2 & 1626 & 95.3 & 3196 & 59.9 \\
\hline \multicolumn{7}{|l|}{ BMI } \\
\hline Normal & 2138 & 58.9 & 1219 & 71.5 & 3357 & 62.9 \\
\hline Underweight & 140 & 3.9 & 174 & 10.2 & 314 & 5.9 \\
\hline Overweight & 1145 & 31.5 & 273 & 16.0 & 1418 & 26.6 \\
\hline Obesity & 209 & 5.8 & 40 & 2.3 & 249 & 4.7 \\
\hline \multicolumn{7}{|l|}{ Study site } \\
\hline Public transportation service company & 61 & 1.7 & 143 & 8.4 & 204 & 3.8 \\
\hline Diamond production plant & 220 & 6.1 & 54 & 3.2 & 274 & 5.1 \\
\hline Dieselengine plant & 550 & 15.1 & 221 & 13.0 & 771 & 14.4 \\
\hline Aluminum production plant & 400 & 11.0 & 5 & 0.3 & 405 & 7.6 \\
\hline Chemical fiber production factory & 187 & 5.1 & 148 & 8.7 & 335 & 6.3 \\
\hline Battery production plant & 115 & 3.2 & 149 & 8.7 & 264 & 4.9 \\
\hline Electrical equipment plant & 1236 & 34.1 & 536 & 31.3 & 1772 & 33.3 \\
\hline Environmental equipment factory & 154 & 4.2 & 55 & 3.2 & 209 & 3.9 \\
\hline Oil equipmentfactory & 129 & 3.6 & 71 & 4.2 & 200 & 3.7 \\
\hline Garment production plant & 63 & 1.7 & 113 & 6.6 & 176 & 3.3 \\
\hline Mechanical equipment fabrication plant & 251 & 6.9 & 78 & 4.6 & 329 & 6.2 \\
\hline Refractory plant & 152 & 4.2 & 66 & 3.9 & 218 & 4.1 \\
\hline Chemical plant & 114 & 3.1 & 67 & 3.9 & 181 & 3.4 \\
\hline
\end{tabular}

week, and 5-7 days per week. An example of the questions is "In the past week, did you feel like a failure?" This scale has been used extensively in China since the 1980s [Zhang et al., 1987]. The Cronbach's $\alpha$ of the CESD for the study population was 0.85 .

\section{Evaluation of Physical Job Characteristics}

The same Dutch musculoskeletal questionnaire was adapted to assess physical job characteristics [Hildebrandt 
et al., 2001]. Physical job demands were assessed according to questions grouped by awkward posture, repetitive motion, manual materials handling, and force exertion. Questions in the awkward posture group included trunk flexion, trunk twisting, arms above shoulders, prolonged working posture (standing, sitting, walking, squatting, kneeling), prolonged neck bending forward or twisting, prolonged bent wrists, prolonged holding objects, and pinch grip. Questions in the repetitive motion group were asked to assess presence of repetitive motion of arms/ hands or trunk per minute. Manual materials handling group included lifting, pushing/pulling and carrying activities for weights greater than $5 \mathrm{~kg}$. Excessive force exertion was assessed by questions about lifting, pushing/pulling and carrying activities $>20 \mathrm{~kg}$ and additional questions about sudden excessive exertions for operating equipment. Two questions about driving vehicles and using vibrating tools were also asked. The answer to each question was dichotomous (yes/no). Additionally, participants' perceived physical demands were measured with five question items by the Job Content Questionnaire (JCQ) [Karasek et al., 1985, 1998]. The Cronbach's $\alpha$ coefficient for perceived physical demands was 0.77 [Yu et al., 2008].

\section{Evaluation of Work-Related Psychosocial Characteristics}

Psychological demands, job control, and the social support dimensions of the job strain model, based on the JCQ, were used in this study [Karasek et al., 1985, 1998]. The reliability and validity of the Chinese version of the job strain model has been established in a previous study [Yu et al., 2008]. Psychological demands were measured with nine items. Job control was assessed by 10 items and social support was assessed by 11 items. The Cronbach's $\alpha$ coefficients for psychological demands, job control, supervisor social support, and coworker social support scales in the study population were $0.60,0.70,0.62$, and 0.65 , respectively.

The questionnaire modeling the effort-reward imbalance (ERI) was also used in this study [Siegrist et al., 2004]. The reliability and validity of the Chinese version of this questionnaire has been established and reported elsewhere [Yu et al., 2008]. The questionnaire consisted of the following three scales: Extrinsic efforts (six items), occupational rewards (11 items), and over-commitment (six items). Extrinsic efforts were evaluated by measuring the psychosocial workload, occupational rewards focusing on the worker's financial status (i.e., salary), self-esteem, and career opportunity (e.g., promotion prospects and job security). Over-commitment as an individual (intrinsic) component was defined as a set of attitudes, behaviors, and emotions reflecting excessive striving along with a strong desire for approval and esteem. Cronbach's $\alpha$ for the effort, reward, and over-commitment scales were 0.78 , 0.58 , and 0.64 , respectively.

Job satisfaction was investigated using the 12 items in the Occupational Stress Indicator related to the job itself, achievement, organizational design and structure, organizational processes, and individual relationships [Cooper et al., 1988; Yu et al., 2000]. The answers to the questions were summed to give a "total job satisfaction" score with a Cronbach's $\alpha$ of 0.93 .

\section{Data Analysis}

The questionnaire data were coded and verified by two researchers by a double data entry method. A descriptive analysis of the prevalence of musculoskeletal symptoms was performed. All the psychosocial factor scores were calculated for all the participants who had no more than three missing values per scale. The missing values of a participant were replaced by the mean of the existing values of other participants on the same scale [Yu et al., 2000; Ahola and Hakanen, 2007].

Logistic regression analyses were performed to estimate the associations between risk factors and musculoskeletal symptoms. The risk factors included individual, physical, and psychosocial characteristics. The psychosocial variables were dichotomized by the median value [Yu et al., 2008]. Univariate and multivariate analyses were carried out for each body region. Statistically significant $(P<10 \%)$ factors in the univariate analysis were included in the multivariate stepwise procedure to form the final model. The significance level at which variables were removed from the final model was set at $5 \%$. A variable was not removed if removal of this variable changed the effect measure significantly. Adjusted odds ratios (ORs) and $95 \%$ confidence intervals (95\% CIs) in the final model were estimated for each significant variable. Because significant differences in the neck, shoulder, and wrist symptoms between the male and female workers were found, analyses for the three body regions were stratified by gender. All the analyses were performed using SPSS 13.0 (SPSS, Inc., Chicago, IL).

\section{RESULTS}

Table II presents the 1-year cumulative prevalence of musculoskeletal symptoms by body region and gender. Tables III-V present the gender-specific risk estimates for the statistically significant variables in the final regression model for symptoms in the neck, shoulders, and wrists. Due to absence of a statistically significant difference between genders, Tables VI and VII show the genderpooled risk estimates for the variables in the final models for symptoms in the elbow, low back, hips, knees, and ankles/feet. 
TABLE II. One-Year Cumulative Prevalence of Musculoskeletal Symptoms in Chinese Workers $(n=5,338)$

\begin{tabular}{|c|c|c|c|c|c|c|}
\hline \multirow[b]{3}{*}{ Body region } & \multicolumn{6}{|c|}{ Symptoms } \\
\hline & \multicolumn{2}{|c|}{ Male } & \multicolumn{2}{|c|}{ Female } & \multicolumn{2}{|c|}{ Total } \\
\hline & $n$ & $\%$ & n & $\%$ & n & $\%$ \\
\hline Low back & 2147 & 59.1 & 1039 & 60.9 & 3186 & 59.7 \\
\hline Neck & 1611 & $44.4^{*}$ & 985 & $57.7^{*}$ & 2596 & 48.6 \\
\hline Shoulders & 1236 & $34.0^{*}$ & 837 & $49.1^{*}$ & 2073 & 38.8 \\
\hline Wrists & 1169 & $32.2^{*}$ & 620 & $36.3^{*}$ & 1789 & 33.5 \\
\hline Ankles/feet & 985 & 27.1 & 456 & 26.7 & 1441 & 27.0 \\
\hline Knees & 913 & 25.1 & 448 & 26.3 & 1361 & 25.5 \\
\hline Hips & 541 & 14.9 & 290 & 17.0 & 831 & 15.6 \\
\hline Elbows & 543 & 15.0 & 266 & 15.6 & 809 & 15.2 \\
\hline
\end{tabular}

${ }^{*} P<0.01$ (Chi-square test).

TABLE III. Results of Adjusted Odds Ratios (95\% Cl) of Risk Factors for 1-Year Cumulative Prevalence of Neck Symptoms $(N=5,338)$

\begin{tabular}{|c|c|c|}
\hline Risk factors & $\operatorname{Men}(N=3,632)$ & Women $(N=1,706)$ \\
\hline \multicolumn{3}{|l|}{ Personal factors } \\
\hline \multicolumn{3}{|l|}{ Age } \\
\hline$\leq 24$ & 1 & 1 \\
\hline $31-40$ & $1.54(1.31-1.81)^{*}$ & $2.51(1.93-3.26)^{*}$ \\
\hline$\geq 41$ & $1.83(1.51-2.22)^{*}$ & $2.92(2.19-3.90)^{*}$ \\
\hline \multicolumn{3}{|l|}{ Educationallevel } \\
\hline Elementary or junior high school & 1 & 1 \\
\hline Highschool & $1.44(1.19-1.74)^{*}$ & - \\
\hline College or university & $1.46(1.15-1.85)^{*}$ & $1.36(1.04-1.79)^{* *}$ \\
\hline \multicolumn{3}{|l|}{ Job title } \\
\hline Worker & 1 & - \\
\hline Assistant worker & $1.48(1.06-2.05)^{* *}$ & - \\
\hline Smoking & $1.18(1.02-1.37)^{* *}$ & - \\
\hline Negative affectivity (reference:Low score) & $1.23(1.05-1.44)^{* *}$ & - \\
\hline Positive affectivity (reference:High score) & $1.27(1.09-1.48)^{*}$ & $1.45(1.14-1.83)^{*}$ \\
\hline Depressive symptoms & $1.23(1.05-1.48)^{*}$ & $1.30(1.03-1.63)^{* *}$ \\
\hline \multicolumn{3}{|l|}{ Physical job characteristics } \\
\hline Prolonged sitting & $1.56(1.29-1.88)^{*}$ & $1.73(1.36-2.20)^{*}$ \\
\hline Prolonged neck bending forward & $2.17(1.86-2.53)^{*}$ & $2.56(2.02-3.24)^{*}$ \\
\hline Prolonged neck twisting & $1.77(1.51-2.09)^{*}$ & $1.67(1.30-2.10)^{*}$ \\
\hline \multicolumn{3}{|l|}{ Psychosocial factors } \\
\hline Job demands & $1.21(1.03-1.42)^{* *}$ & $1.44(1.11-1.86)^{*}$ \\
\hline Effort & $1.56(1.33-1.83)^{*}$ & $1.52(1.18-1.97)^{*}$ \\
\hline Over-commitment & - & $1.44(1.14-1.82)^{*}$ \\
\hline Job dissatisfaction & - & $1.34(1.06-1.70)^{* *}$ \\
\hline
\end{tabular}


TABLE IV. Results of Adjusted Odds Ratios ( $95 \% \mathrm{Cl}$ ) of Risk Factors for 1-Year Cumulative Prevalence of Shoulder Symptoms $(N=5,338)$

\begin{tabular}{|c|c|c|}
\hline Risk factors & $\operatorname{Men}(N=3,632)$ & Women $(N=1,706)$ \\
\hline \multicolumn{3}{|l|}{ Personal factors } \\
\hline \multicolumn{3}{|l|}{ Age } \\
\hline$\leq 24$ & 1 & 1 \\
\hline $31-40$ & $1.33(1.13-1.57)^{*}$ & $1.75(1.36-2.25)^{*}$ \\
\hline$\geq 41$ & $1.55(1.28-1.88)^{*}$ & $2.03(1.54-2.68)^{*}$ \\
\hline \multicolumn{3}{|l|}{ Educational level } \\
\hline Elementary or junior high school & - & 1 \\
\hline High school & - & $1.76(1.35-2.28)^{*}$ \\
\hline College or university & - & $1.95(1.43-2.67)^{*}$ \\
\hline Negative affectivity (reference:Low score) & $1.20(1.02-1.42)^{* *}$ & - \\
\hline Positive affectivity (reference:High score) & - & $1.34(1.07-1.67)^{*}$ \\
\hline Depressive symptoms & $1.20(1.07-1.50)^{*}$ & $1.24(1.00-1.54)^{* *}$ \\
\hline \multicolumn{3}{|l|}{ Physical job characteristics } \\
\hline Prolonged sitting & $1.40(1.17-1.67)^{*}$ & $1.43(1.13-1.79)^{*}$ \\
\hline Working with hands above shoulders & - & $1.59(1.22-2.02)^{*}$ \\
\hline Working with hands in awkward posture & $1.29(1.10-1.51)^{*}$ & - \\
\hline Prolonged neck bending forward & $1.64(1.39-1.92)^{*}$ & $1.87(1.48-2.36)^{*}$ \\
\hline Prolonged neck twisting & $1.78(1.51-2.11)^{*}$ & $1.59(1.25-2.02)^{*}$ \\
\hline \multicolumn{3}{|l|}{ Psychosocial factors } \\
\hline Job demands & $1.21(1.03-1.43)^{* *}$ & $1.37(1.08-1.75)^{* *}$ \\
\hline Effort & $1.44(1.23-1.70)^{*}$ & $1.35(1.06-1.72)^{* *}$ \\
\hline Reward & $1.26(1.07-1.49)^{*}$ & - \\
\hline Over-commitment & - & $1.42(1.13-1.77)^{*}$ \\
\hline
\end{tabular}

Regarding individual factors, two age groups from 31 to 40 and $\geq 40$ years were associated with the musculoskeletal symptoms in the neck, shoulders, elbows, low back, hips, and knees. Education level of high school or above (college, or university) was associated with the neck symptoms in both genders and the shoulder symptoms in women. Smoking was related to the neck symptoms in men with a relative low OR of 1.18. Increased BMI values were linked to increased reporting of musculoskeletal symptoms in the knees and ankles/feet in both genders and the wrists in women. Positive affect was statistically significantly associated with the neck symptoms in both genders and the shoulder symptoms in women with moderate ORs ranging from 1.2 to 1.45 . Negative affect was statistically significantly linked to the symptoms in most body regions, except the neck and shoulders in women and wrists in both genders. Statistically significant associations between depressive symptoms and musculoskeletal symptoms were found present in all body regions.

Many physical risk factors were found to be statistically significant risk estimates (ORs between 1 and 3 ) for musculoskeletal symptoms. The neck and shoulder symptoms were statistically significantly associated with prolonged sitting, neck bending forward, and neck twisting; while shoulder symptoms were statistically significantly associated with two additional physical risk factors including working with hands above shoulders and working in awkward hand posture. Using vibrating tools, pinch grip, repetitive hand movements, and prolonged awkward wrist postures were statistically significantly linked to the wrist symptoms. Using vibrating tools and exerting excessive forces with arms and hands were the two statistically significant physical risk factors for the elbow symptoms. Excessive force exertions, lifting in awkward posture, carrying heavy loads $>20 \mathrm{~kg}$, trunk twisting, prolonged kneeling/squatting, and working without supporting body weight were the statistically significant physical risk factors for the low back symptoms. The symptoms in the hips were related to pushing/pulling heavy loads $>20 \mathrm{~kg}$ and prolonged working in kneeling/squatting posture. The symptoms in the knees and ankles/feet were primarily associated with prolonged working postures with an exception that prolonged sitting had a reversed risk estimate 
TABLE V. Results of Adjusted Odds Ratios ( $95 \% \mathrm{Cl}$ ) of Risk Factors for 1-Year Cumulative Prevalence of Wrist Symptoms $(N=5,338)$

\begin{tabular}{|c|c|c|}
\hline Risk factors & $\operatorname{Men}(\mathrm{N}=3632)$ & Women $(N=1706)$ \\
\hline \multicolumn{3}{|l|}{ Personal factors } \\
\hline \multicolumn{3}{|l|}{ Job title } \\
\hline Workers & 1 & - \\
\hline Managers & $1.88(1.45-2.44)^{*}$ & - \\
\hline \multicolumn{3}{|l|}{ BMI } \\
\hline Normal & - & 1 \\
\hline Overweight & - & $1.39(1.04-1.84)^{* *}$ \\
\hline Depressive symptoms & $1.40(1.19-1.63)^{*}$ & $1.51(1.21-1.88)^{*}$ \\
\hline \multicolumn{3}{|l|}{ Physical job characteristics } \\
\hline Prolonged wrist bending & $1.51(1.27-1.80)^{*}$ & - \\
\hline Prolonged wrist twisting & $1.46(1.22-1.73)^{*}$ & $2.88(2.29-3.62)^{*}$ \\
\hline Exerting great forces with arms or hands & $1.22(1.03-1.43)^{* *}$ & - \\
\hline Holding things in a pinch grip & - & $1.39(1.09-1.76)^{*}$ \\
\hline Repetitive movements of hands & $1.30(1.09-1.55)^{*}$ & $1.47(1.11-1.93)^{*}$ \\
\hline Using vibrating tools & $1.22(1.04-1.44)^{* *}$ & $1.48(1.13-1.94)^{*}$ \\
\hline \multicolumn{3}{|l|}{ Psychosocial factors } \\
\hline Job control & - & $1.45(1.16-1.81)^{*}$ \\
\hline Effort & $1.45(1.24-1.69)^{*}$ & $1.46(1.16-1.85)^{*}$ \\
\hline Over-commitment & - & $1.36(1.08-1.71)^{*}$ \\
\hline Job dissatisfaction & $1.42(1.21-1.67)^{*}$ & - \\
\hline
\end{tabular}

$(\mathrm{ORs}<1)$ for the symptoms. Perceived physical demands measured by the JCQ showed a range of statistically significant ORs from 1 to 2 .

Many psychosocial factors including psychological demands, low job control, effort, reward, over-commitment, and job dissatisfaction were found to be statistically significantly associated with the musculoskeletal symptoms in different body regions with moderate ORs between 1 and 2 .

\section{DISCUSSION}

\section{Prevalence of Musculoskeletal Symptoms}

The highest prevalence of musculoskeletal symptoms among all the body regions was the low back (59.7\%), followed by the neck $(48.6 \%)$, shoulders $(38.8 \%)$, wrists (33.5\%), ankles/feet $(27.0 \%)$, knees $(25.5 \%)$, hips $(15.6 \%)$, and elbows (15.2\%). Jin et al. [2004] reported the overall self-reported annual prevalence of low back pain among workers from three Shanghai factories in China was about 50\%. Chen et al. [2005] reported that among 561 sampled Chinese offshore oil installation workers, the highest prevalence of musculoskeletal pain over the previous 12 months was in the low back (32.4\%), followed by the neck (25\%), knees $(20.1 \%)$, shoulders (20\%) and other body regions (8.4-13.7\%). The large discrepancies in the prevalence of the work-related musculoskeletal symptoms between Chen's and the present studies were likely due to different occupations surveyed and some healthy worker effects of the oil installation workers [Chen et al., 2005].

Results of the present study on prevalence of musculoskeletal symptoms were similar to the findings in telecommunication workers in the European Union [Crawford et al., 2008]. In the British population, the prevalence of occupational neck pain in various occupations ranged from 29 to $38 \%$ with the highest rate for male construction workers [Palmer et al., 2001]. A study with a large sample size of over 1,500 workers from a bi-annual US national survey database revealed that the prevalence of reported musculoskeletal pain in low back and arms was both about $28 \%$ [Waters et al., 2007]. The prevalence of the musculoskeletal symptoms in the present study, however, was greater than the two aforementioned populationbased studies. Possible contributing factors of the differences may include magnitudes of the exposure to the risk factors for musculoskeletal symptoms as well as surveillance measures and techniques used in the studies, such as 
TABLE VI. Results of Adjusted Odds Ratios $(95 \% \mathrm{Cl})$ of Risk Factors for 1-Year Cumulative Prevalence of Elbow and Low Back Symptoms $(\mathrm{N}=5,338)$

\begin{tabular}{|c|c|c|}
\hline Risk factors & Elbows & Low back \\
\hline \multicolumn{3}{|l|}{ Personal factors } \\
\hline \multicolumn{3}{|l|}{ Age } \\
\hline$\leq 24$ & 1 & 1 \\
\hline $31-40$ & - & $2.07(1.64-2.61)^{*}$ \\
\hline$\geq 41$ & $1.88(1.58-2.23)^{*}$ & $1.96(1.50-2.56)^{*}$ \\
\hline \multicolumn{3}{|l|}{ Job title } \\
\hline Worker & 1 & - \\
\hline Manager & $1.80(1.36-2.38)^{*}$ & - \\
\hline Negative affectivity (reference:Lowscore) & $1.24(1.04-1.47)^{* *}$ & $1.25(1.01-1.56)^{* *}$ \\
\hline Depressive symptoms & $1.48(1.24-1.76)^{*}$ & $1.38(1.11-1.72)^{*}$ \\
\hline \multicolumn{3}{|l|}{ Physical job characteristics } \\
\hline Using vibrating tools & $1.29(1.09-1.52)^{*}$ & - \\
\hline Exerting great forces with arms or hands & $1.37(1.14-1.64)^{*}$ & $1.33(1.03-1.73)^{* *}$ \\
\hline Lifting in awkward posture & - & $1.37(1.09-1.72)^{*}$ \\
\hline Carrying very heavy loads $>20 \mathrm{~kg}$ & - & $1.32(1.05-1.65)^{* *}$ \\
\hline Trunk twisting & - & $1.32(1.06-1.65)^{* *}$ \\
\hline Prolonged kneeling/squatting & - & $1.39(1.10-1.74)^{*}$ \\
\hline Working without support for body weight & - & $1.33(1.07-1.65)^{* *}$ \\
\hline Physical demands & $1.42(1.19-1.70)^{*}$ & $1.35(1.08-1.68)^{*}$ \\
\hline \multicolumn{3}{|l|}{ Psychosocial factors } \\
\hline Effort & $1.48(1.25-1.77)^{*}$ & - \\
\hline Job dissatisfaction & $1.39(1.16-1.65)^{*}$ & $1.39(1.11-1.73)^{*}$ \\
\hline
\end{tabular}

case definition (symptoms lasting more than 1 vs. 7 days), timing of survey in relation to progression of pain symptom, study design, and sampling bias.

\section{Risk Factors Associated with Musculoskeletal Symptoms}

Many studies showed age as a risk factor for neck and shoulder symptoms [Hagen et al., 1998; Gerr et al., 2002; Cassou et al., 2002; Leroux et al., 2005; Leroyer et al., 2006; Lindfors et al., 2006; Andersen et al., 2008; Tornqvist et al., 2009], for low back symptoms [Hagen et al., 1998; Leroux et al., 2005], and for symptoms in the ankles/feet [Messing et al., 2008], but some studies indicated that age was not a risk factor for neck or shoulder symptoms [Croft et al., 2001; Leroux et al., 2006], for hand or wrist symptoms [Gerr et al., 2002; Ortiz-Hernández et al., 2003; Lassen et al., 2004; Leroux et al., 2005], and for low back symptoms [Ortiz-Hernández et al., 2003; Ijzelenberg et al., 2004; Waters et al., 2007]. One possible explanation for the mixed results in the literature is that age may have an underlying effect on biomechanical or psychosocial risk factors, which might be difficult to control for in the analysis models [NIOSH, 1997]. The age factor was also likely to be influenced by the study population in China, where most blue collar or production workers retired before age 50 . The competitive labor market (i.e., ample supply of young workers) in China often forced older workers to retire early to avoid health costs to employers. This cultural factor limited the researchers from analyzing the age factor greater than 50 years, leading to a difficulty in understanding the effects of the full range of age on the development of musculoskeletal problems in the Chinese working population.

The effect of gender on musculoskeletal symptoms in the present study is consistent with many published studies [Skov et al., 1996; Croft et al., 2001; Gerr et al., 2002; Karlqvist et al., 2002; Lundberg, 2002; Jensen 2003; Kryger et al., 2003; Hooftman et al., 2004; JuulKristensen et al., 2004; Leroux et al., 2005; Leroyer et al., 2006; Andersen et al., 2008; Tornqvist et al., 2009]. It has been suggested that the gender difference in reporting musculoskeletal pain may be caused by biological differences in load-tolerance relationship, differences in work methods resulting in different risk exposure levels, thresholds for pain perception and job assignments [Jager 
TABLE VII. Results of Adjusted Odds Ratios (95\% Cl) of Risk Factors for 1-Year Cumulative Prevalence of Musculoskeletal Symptoms in the Hips, Knees, and Ankles/Feet $(\mathrm{N}=5,338)$

\begin{tabular}{|c|c|c|c|}
\hline Risk factors & Hips & Knees & Ankles/feet \\
\hline \multicolumn{4}{|l|}{ Personal factors } \\
\hline \multicolumn{4}{|l|}{ Age } \\
\hline$\leq 24$ & 1 & 1 & - \\
\hline $31-40$ & $1.50(1.26-1.79)^{*}$ & $1.52(1.31-1.77)^{*}$ & - \\
\hline$\geq 41$ & $1.67(1.36-2.04)^{*}$ & $2.34(1.97-2.77)^{*}$ & - \\
\hline \multicolumn{4}{|l|}{ Educational level } \\
\hline Elementary or junior high school & - & - & 1 \\
\hline Highschool & - & - & $1.23(1.07-1.40)^{*}$ \\
\hline \multicolumn{4}{|l|}{ BMI } \\
\hline Normal & - & 1 & 1 \\
\hline Overweight & - & $1.32(1.14-1.52)^{*}$ & - \\
\hline Obesity & - & $1.53(1.15-2.03)^{*}$ & $1.35(1.02-1.79)^{* *}$ \\
\hline Negative affectivity (reference:Low score) & $1.41(1.19-1.67)^{*}$ & $1.44(1.25-1.67)^{*}$ & $1.37(1.19-1.58)^{*}$ \\
\hline Depressive symptoms & $1.54(1.30-1.83)^{*}$ & $1.26(1.09-1.46)^{*}$ & $1.30(1.12-1.49)^{*}$ \\
\hline \multicolumn{4}{|l|}{ Physical job characteristics } \\
\hline Work shift & - & - & $1.26(1.10-1.44)^{*}$ \\
\hline Pushing/pulling heavyloads $>20 \mathrm{~kg}$ & $1.29(1.10-1.51)^{*}$ & - & - \\
\hline Prolonged kneeling/squatting & $1.61(1.24-2.09)^{*}$ & $1.39(1.18-1.64)^{*}$ & $1.28(1.09-1.51)^{*}$ \\
\hline Prolonged standing & - & $1.26(1.07-1.48)^{*}$ & $1.53(1.29-1.81)^{*}$ \\
\hline Prolonged sitting & - & $0.82(0.70-0.97)^{* *}$ & $0.77(0.65-0.91)^{*}$ \\
\hline Prolonged walking & - & - & $1.23(1.06-1.43)^{*}$ \\
\hline Physical demands & $1.48(1.25-1.76)^{*}$ & $1.27(1.10-1.47)^{*}$ & $1.31(1.14-1.51)^{*}$ \\
\hline \multicolumn{4}{|l|}{ Psychosocial factors } \\
\hline Effort & $1.42(1.20-1.68)^{*}$ & $1.26(1.09-1.47)^{*}$ & $1.27(1.10-1.46)^{*}$ \\
\hline Job control & $1.24(1.06-1.45)^{*}$ & - & - \\
\hline Job dissatisfaction & - & $1.19(1.04-1.38)^{* *}$ & $1.42(1.24-1.64)^{*}$ \\
\hline
\end{tabular}

et al., 1991; Lundberg, 2002; Hallin, 2003; Norman et al., 2008; Tornqvist et al., 2009].

Our study findings suggest that both male and female workers with higher education levels, most likely managerial or office workers, are at higher risk of reporting neck symptoms. Female workers with higher education levels are at risk of reporting additional shoulder symptoms. The findings are not in agreement with some studies [OrtizHernández et al., 2003; Tornqvist et al., 2009], in which no correlation of educational level with any MSDs was found. Information about detailed type of work (such as use of computer) in relation to education level may help elucidate the potential confounding effect.

Some researchers have found a similar positive association between smoking and musculoskeletal symptoms [Brage and Bjerkedal, 1996; da Costa and Vieira, 2010]. Most studies linking smoking to MSDs focused on low back disorders in clinical settings. It is suggested that the causal mechanism of smoking for some forms of MSDs is associated with the interference with nutrition delivery to the spinal structures [Battie et al., 1991]. However, supporting evidence on the association of smoking and MSDs in the epidemiologic literature is very limited. The present study adds limited evidence to the effects of smoking on neck symptoms.

The link between high BMI and musculoskeletal symptoms is suggested in many studies [Coggon et al., 2000; Roquelaure et al., 2001; Nathan et al., 2002; Leroux et al., 2005; Werner et al., 2005; Anderson et al., 2007]. Our findings provide new evidence to support the link but primarily between BMI and musculoskeletal symptoms in the lower extremities.

Depression was the only assessed factor found to be statistically significantly associated with the musculoskeletal symptoms in all body regions in both genders. There is no clear empirical evidence in the literature showing the causal mechanism of depression in relation to musculoskeletal symptoms. Depressive symptoms were 
summarized to have a positive association with MSDs in a review study [Bongers et al., 2006]. It is plausible that depressive symptoms may have underlying mechanisms to influence musculoskeletal pain either through the route to reporting pain or the route to biomechanical or physical strain [Sauter and Swanson, 1996]. However, it is equally plausible that depressive symptoms could be influenced by the musculoskeletal symptoms, not the reverse. If this reciprocal effect is true, the impact of MSDs may have implications for co-morbidity, causing amplified effects of the existing MSD problem.

Literature about affectivity primarily focuses on psychiatric disorders such as anxiety and depressive disorders [Watson and Pennebaker, 1989]. Negative affectivity in relation to musculoskeletal pain was examined in a limited number of studies [Bergqvist et al., 1995; Joksimovic et al., 2002; Lassen et al., 2004]. We found that increased negative affectivity was associated with musculoskeletal symptoms in all body regions except the neck and shoulders in women and wrists in both genders, indicating that our findings are in agreement with most previous studies [Bergqvist et al., 1995; Joksimovic et al., 2002]. To our knowledge, the present study was the first attempt to examine the association between positive affectivity and musculoskeletal symptoms in multiple body regions. Our findings revealed a significant association between decreased positive affectivity and musculoskeletal symptoms in the neck and shoulders. Although the two affect dimensions are independent of each other [Harding, 1982], an association between musculoskeletal symptoms and decreased positive affectivity (or increased negative affectivity) was found. The finding may be linked to a tendency of reporting symptoms [Watson and Pennebaker, 1989] or the decreased threshold at which pain is perceived [Gheldof et al., 2006]. The two effect scores may also be influenced by some work-related psychosocial factors [Sauter and Swanson, 1996]. Our finding suggests that more research be conducted to explore the associations.

Generally, prolonged awkward postures, lifting, pushing/pulling and carrying heavy loads (>20 kg), exerting excessive forces with arms and hands were significant risk estimates for musculoskeletal symptoms in multiple body regions. The study findings are in agreement with several critical review studies on the physical risk factors for WMSDs [NIOSH, 1997; Hoogendoorn et al., 2001; NAS, 2001; da Costa and Vieira, 2010]. It should be pointed out that the lower ORs (range of 1-3) of the physical risk factors found in the present study were likely to be influenced by the sensitivity of the questionnaire method, as compared to robust risk quantifications using biomechanical models [Marras et al., 2010].

Few researchers have looked at the impact of dimensions of job demand-control and the ERI models on the prevalence of various types of musculoskeletal symptoms simultaneously. Adjusted for a variety of individual and physical job factors, none of the psychosocial factors showed a consistent correlation with all the musculoskeletal symptoms. This finding may lead to a hypothesis that intensity or type (chronic vs. acute) of self-reported musculoskeletal pain in different body regions may have a potential effect on the strength of the psychosocial factors in association with the reported pain.

The role that job dissatisfaction plays in the development of MSDs is still unclear. Similar to the above-mentioned psychosocial factors, job dissatisfaction was associated with the musculoskeletal symptoms in some but not all body regions. The direction of the findings about job dissatisfaction in the present study is in line with the majority of the published studies: The higher level of job dissatisfaction, the higher the OR for musculoskeletal symptoms [da Costa and Vieira, 2010]. The ORs (=1.19-1.42) of job dissatisfaction for musculoskeletal symptoms found in the present study, however, were smaller than those $(\mathrm{OR}=1.89-7.65)$ found in other studies [Bigos et al., 1991; Marras et al., 1995; Waters et al., 2011]. It is difficult to compare the strength of job dissatisfaction in relation to the musculoskeletal pain because there are seven main types of survey instruments for job satisfaction used in the literature [van Saane et al., 2003]. The effects of job dissatisfaction on musculoskeletal symptoms cannot be clearly identified until the survey instruments and data comparison methodologies are unified.

\section{Limitations}

The study is subject to the limitations associated with a cross-sectional study design, such as limited causal inferences and healthy worker effects, etc. Potential recall biases due to self-report health survey for the previous year might exist. Non-work-related variables were not measured and taken into account in our data analysis. Self-reported physical risk exposure measures might not be as accurate as objective measures, such as video task/ posture analyses, force measurements, and biomechanical modeling, which, however, are typically involved in laborintensive and costly data collection. Nevertheless, the limitations are typical in epidemiological studies for workrelated musculoskeletal symptoms using a questionnaire method and should not void our study findings for a preliminary investigation of the musculoskeletal health problem in many industrial settings in China.

\section{CONCLUSIONS}

The study provides comprehensive information about the current musculoskeletal health conditions of workers in many industrial settings in Henan province, China. 
Multiple risk areas including individual, physical job demands, and work-related psychosocial factors were found to be associated with musculoskeletal symptoms in different body regions. It is suggested that interventions aimed at reducing prevalence of musculoskeletal symptoms in Chinese workers take into account these different risk areas.

\section{ACKNOWLEDGMENTS}

We are grateful to all the volunteers who participated in this study. The authors express deepest appreciation to Mr. Shiyi Sun, Xiaofa Yang, Shouming Cui, Haisheng Wang, Shule Yang, and Zengchao Wang for their help in the study. This research was supported by National Science and Technology Infrastructure Program (2006BA I06B 08), China.

\section{REFERENCES}

Ahola K, Hakanen J. 2007. Job strain, burnout, and depressive symptoms: A prospective study among dentist. J Affect Disor 104: 103-110.

Anderson JH, Haahr JP, Frost P. 2007. Risk factors for more severe regional musculoskeletal symptoms: A two-tear prospective study of a general working population. Arthritis Rheum 56:1355-1364.

Andersen JH, Harhoff M, Grimstrup S, Vilstrup I, Lassen CF, Brandt L, Kryger AI, Overgaard E, Hansen KD, Mikkelsen S. 2008. Computer mouse use predicts acute pain but not prolonged or chronic pain in the neck and shoulder. Occup Environ Med 65:126131.

Battie M, Videman T, Gill K, Moneta GB, Nyman R, Kaprio J, Koskenvuo M. 1991. Smoking and lumbar intervertebral disc degeneration: An MRI study of identical twins. Spine 16:1015-1021.

Bergqvist U, Wolgast E, Nilsson B, Voss M. 1995. Musculoskeletal disorders among visual display terminal workers: Individual, ergnomic, and work organization factors. Ergonomics 38:763-776.

Bigos SJ, Battie MC, Spengler DM, Fisher LD, Fordyce WE, Hansson TH, Nachemson AL, Wortley MD. 1991. A prospective study of work perceptions and psychosocial factors affecting the report of back injury. Spine 16:1-6.

Bongers PM, Ijmker S, van den Heuvel S, Blatter BM. 2006. Epidemiology of work related neck and upper limb problems: Psychosocial and personal risk factors. (PartI) and effective interventions from a bio behavioural perspective (Part II). J Occup Rehabil $16: 279-302$.

Bradburn N. 1969. The structure of psychological well-being. Chicago: Aldine.

Brage S, Bjerkedal T. 1996. Musculoskeletal pain and smoking in Norway. J Epidemiol Community Health 50:166-169.

Cassou B, Derriennic F, Monfort C, Norton J, Touranchet A. 2002. Chronic neck and shoulder pain, age, and working conditions: Longitudinal results from a large random sample in France. Occup Environ Med 59:537-544.

Chen WQ, Yu IT, Wong TW. 2005. Impact of occupational stress and other psychosocial factors on musculoskeletal pain among
Chinese offshore oil installation workers. Occup Environ Med 62: 251-256.

Coggon D, Croft P, Kellingray S. 2000. Occupational physical activities and oseteoarthritis of the knee. Arthritis Rheum 43:1443-1449.

Cooper CL, Sloan SJ, Williams S. 1988. The occupational stress indicator. Winsdor: NFER-NELSON Publishing Company Limited.

Coyte PC, Asche CV, Croxford R, Chan B. 1998. The economic cost of musculoskeletal disorders in Canada. Arthritis Care Res 11:315325 .

Crawford JO, Laiou E, Spurgeon A, McMillan G. 2008. Musculoskeletal disorders within the telecommunications sector-A systematic review. Int J Ind Ergonomics 38:56-72.

Croft PR, Lewis M, Papageorgiou AC, Thomas E, Jayson M, Macfarlane GJ, Silman AJ. 2001. Risk factors for neck pain: A longitudinal study in the general population. Pain 93:317-325.

da Costa BR, Vieira ER. 2010. Risk factors for work-related musculoskeletal disorders: A systematic review of recent longitudinal studies. Am J Ind Med 53:285-323.

Gerr F, Marcus M, Ensor C, Kleimbaum D, Cohen S, Edwards A, Gentry E, Ortiz D, Monteilh C. 2002. A prospective study of computer users: I. Study design and incidence of musculoskeletal symptoms and disorders. Am J Ind Med 41:221-235.

Gheldof E, Vinck J, van den Bussche E, Vlaeyen J, Hidding A, Crombez G. 2006. Pain and pain-related fear are associated with functional and social disability in an occupational setting: Evidence of mediation by pain-related fear. Euro J Pain 10:513-525.

Hagen KB, Magnus P, Vetlesen K. 1998. Neck/shoulder and lowback disorders in the forestry industry: Relationship to work task and perceived psychosocial job stress. Ergonomics 41:1510-1518.

Hallin RG. 2003. Pain more painful in women. Gender perspective neglected in research on the biological mechanisms of pain Lakartidningen 100:3738-3741

Harding S. 1982. Psychological well-being in Great Britain: An evaluation of the Bradburn affect balance scale. Person Individ Diff $3: 167-175$

Hildebrandt VH, Bongers PM, van Dijk FJH, Kemper HCG, Dul, J. 2001. Dutch musculoskeletal questionnaire: Description and basic qualities. Ergonomics 44:1038-1055.

Hooftman W, van Poppel MNM, van der Beek AJ, Bongers Pm, van Mechelen W. 2004. Gender differences in the relation between work related physical and psychosocial risk factors and musculoskeletal complaints. Scand J Work Environ Health 30:261278.

Hoogendoorn WE, Bongers PM, de Vet HC, Houtman I, Ariens G, van Mechelen W, Bouter LM. 2001. Psychosocial work characteristics and psychological strain in relation to low-back pain. Scand J Work Environ Health 27:258-267.

Ijzelenberg W, Molenaar D, Burdorf A. 2004. Different risk factors for musculoskeletal complaints and musculoskeletal sickness absence. Scand J Work Environ Health 30:56-63.

Jager M, Luttmann A, Laurie W. 1991. Lumbar load during onehanded bricklaying. Int J Ind Ergonomics 8:261-277.

Jensen C. 2003. Development of neck and hand-wrist symptoms in relation to duration of computer use at work. Scand J Work Environ Health 29:197-205.

Jin K, Sorock GS, Courtney TK. 2004. Prevalence of low back pain in three occupational groups in Shanghai, People's Republic of China. J Safety Res 35:23-28. 
Joksimovic L, Starke D, von dem Knesebeck O, Siegrist J. 2002 Perceived work stress, overcommitment, and self-reported musculoskeletal pain: A cross-sectional investigation. Int J Behav Med 9: $122-138$.

Juul-Kristensen B, Søgaard K, Strøyer J, Jensen C. 2004. Computer users' risk factors for developing shoulder, elbow and back symptoms. Scand J Work Environ Health 30:390-398.

Karasek R, Gordon G, Pietrokovsky C, Frese M, Pieper C, Schwartz J, Fry L, Schirer D. 1985. Job content instrument: Questionnaire and users' guide. Revision 1.1. Lowell (MA): University of Massachusetts.

Karasek R, Brisson C, Kawakami N., Houtman I, Bongers P, Amick B. 1998. The Job Content Questionnaire (JCQ): An instrument for internationally comparative assessments of psychosocial job characteristics. J Occup Health Psychol 3:322-355.

Karlqvist L, Tornqvist EW, Hagberg M, Hagman M, Toomingas A. 2002. Self- reported working conditions of VDU operators and associations with musculoskeletal symptoms: A cross-sectional study focusing on gender differences. Int J Ind Ergonomics 30:277294.

Kryger AI, Andersen JH, Lassen CF, Brandt LPA, Vilstrup I, Overgaard E, Thomsen JF, Mikkelsen S. 2003. Does computer use pose an occupational hazard for forearm pain; from the NUDATA study. Occup Environ Med 60:e14.

Lassen CF, Mikkelsen S, Kryger AI, Brandt LPA, Overgaard E, Thomsen JF, Vilstrup I, Andersen JH. 2004. Elbow and wrist/hand symptoms among 6,943 computer operators: A 1-year follow-up study (The NUDATA study). Am J Ind Med 46:521-533.

Leroux I, Dionne CE, Bourbonnais R, Brisson C. 2005. Prevalence of musculoskeletal pain and associated factors in the Quebec working population. Int Arch Occup Environ Health 78:379-386.

Leroux I, Brisson C, Montreuil S. 2006. Job strain and neckshoulder symptoms: A prevalence study of women and men whitecollar workers. Occup Med 56:102-109.

Leroyer A, Edmé JL, Vaxevanoglou X, Buisset C, Laurent P, Desobry P, Frimat P. 2006. Neck, shoulder, and hand and wrist pain among administrative employees: Relation to work-time organization and psychosocial factors at work. J Occup Environ Med 48:326-333.

Liberty Mutual Research Institute for Safety. 2009. Liberty Mutual Workplace Safety Index, Liberty Mutual 175 Berkeley. St. Boston, MA 02116: Liberty Mutual Research Institute for Safety.

Lindfors P, von Thiele U, Lundberg U. 2006. Work characteristics and upper extremity disorders in female dental health workers. J Occup Health 48:192-197.

Lundberg U. 2002. Psychophysiology of work: Stress, gender, endocrine response, and work-related upper extremity disorders. Am J Ind Med 41:383-392.

Marras WS, Lavender SA, Leurgans SE, Fathallah FA, Ferguson SA, Allread WG. 1995. Biomechanical risk factors for occupationally related low back disorders. Ergonomics 38:377-410.

Marras WS, Lavender SA, Ferguson SA, Splittstoesser RE, Yang G. 2010. Quantitative biomechanical workplace exposure measures: Distribution centers. J Electromyogr Kinesiol 20:813-822.

Messing K, Tissot F, Stock S. 2008. Distal lower-extremity pain and work postures in the Quebec population. Am J Public Health 98:705-713.

Nathan PA, Meadows KD, Istvan JA. 2002. Predictors of carpal tunnel syndrome: An 11-year study of industrial workers. Hand Surgery Am 27:644-651.
National Academy of Science, Research Council and Institute of Medicine. 2001. Musculoskeletal disorders and the workplace. Low back and upper extremities. Washington DC: National Academy Press.

National Institute for Occupational Safety and Health. 1997. Musculoskeletal disorders and workplace factors, a critical review of epidemiologic evidence for work-related musculoskeletal disorders of the neck, upper extremity and low back. Cincinnati, Ohio: U.S. Department of Health and Human Services.

Norman K, Floderus B, Hagman M, Toomingas A, Tornqvist EW 2008. Musculoskeletal symptoms in relation to work exposure at call center companies in Sweden. Work 30:201-214.

Ortiz-Hernández L, Tamez-González S, Martínez-Alcántara S, Mendez-Ramirez I. 2003. Computer use increases the risk of musculoskeletal disorders among newspaper office workers. Arch Med Res 34:331-342.

Palmer KT, Walker-Bone K, Griffin MJ, Syddall H, Pannett B, Coggon D, Cooper C. 2001. Prevalence and occupational associations of neck pain in the British population. Scand J Work Environ Health 27:49-56.

Radloff LS. 1977. The CES-D scale: A self-report depression scale for research in the general population. Appl Psychol Meas 1:385401.

Roquelaure Y, Mariel J, Dano C, Fanello S, Penneau-Fontbonne D. 2001. Prevalence, incidence, and risk factors of carpal tunnel syndrome in a large footwear factory. Int J Occup Med Environ Health 14:357-367.

Sauter SL, Swanson NG. 1996. An ecological model of musculoskeletal disorders in office work. In: Moon SD, Sauter SL, editors. Beyond biomechanics: Psychosocial aspects of musculoskeletal disorders in office work. London: Taylor and Francis. 3$21 \mathrm{p}$

Siegrist J, Starke D, Chandola T, Gordin I, Marmot M, Niedhammer I, Peter R. 2004. The measurement of effort-reward imbalance at work: European comparisons. Soc Sci Med 58:1483-1499.

Skov T, Borg V, Ørhede E. 1996. Psychosocial and physical risk factors for musculoskeletal disorders of the neck, shoulders, and lower back in salespeople. Occup Environ Med 53:351-356.

Smith DR, Wei N, Zhao L, Wang R. 2004. Musculoskeletal complaints and psychosocial risk factors among Chinese hospital nurses. Occup Med 54:579-582.

Thienoff R. 2002. Economic significance of work disability caused by musculoskeletal disorders. Orthopade 31:949-956.

Tornqvist EW, Hagberg M, Hagman M, Risberg EH, Toomingas A. 2009. The influence of working conditions and individual factors on the incidence of neck and upper limb symptoms among professional computer users. Int Arch Occup Environ Health 82:689-702.

United States Bureau of Labor Statistics. 2009. Nonfatal occupational injuries and illnesses requiring days away from work in 2008 . Washington DC: United States Bureau of Labor Statistics.

van Saane N, Sluiter JK, Verbeek HAM, Frings-Dresen MHW. 2003. Reliability and validity of instruments measuring job satisfaction-a systematic review. Occup Med 53:191-200.

Waters T, Dick R, Davis-Barkley J, Krieg E. 2007. A Cross-sectional study of risk factors for musculoskeletal symptoms in the workplace using data from the General Social Survey (GSS). J Occup Environ Med 49(2):172-184.

Waters T, Lu M, Piacitelli L, Werren D, Deddens J. 2011. Efficacy of the revised NIOSH lifting equation to predict risk of low back 
pain due to manual lifting. Expanded cross-sectional analysis. J Occup Environ Med 53:1061-1067.

Watson D, Clark LA. 1988. Positive and negative affectivity and their relation to anxiety and depressive disorders. J Abnorm Psychol 97:346-353.

Watson D, Pennebaker JW. 1989. Health complaints, stress, and distress: Exploring the central role of negative affectivity. Psychol Rev 96:234-254.

Werner RA, Franzblau A, Gell N, Ulin SS, Armstrong TJ. 2005. A longitudinal study of industrial and clerical workers: Predictors of upper extremity tendonitis. J Occup Rehabil 15: $37-46$.
Yang L, Hildebrandt HV, Yu S, Lin R, He L, Xia Z, Wang J, Li L, Wang S. 2009. Introduction of musculoskeletal disorders questionnaire. Ind Hyg Occup Dis (in Chinese) 35:12-15.

Yu S, Zhang R, Ma L, Liu C, Deng Y, Gu G. 2000. Study of the occupational stress measure instruments (In Chinese). Henan Med Res 9:171-174.

Yu S, Gu G, Zhou W, Wang S. 2008. Psychosocial work environment and wellbeing: A cross-sectional study at a thermal power plant in China. J Occup Health 50:155-162.

Zhang M, Ren F, Fan B. 1987. Investigation of depressive symptoms among normal populations and application of CES-D (In Chinese). Chinese J Neurol Psychiatr 20:67-71. 